\title{
The vigor of defense against non-self: potential superiority of allorestricted T cells in immunotherapy of cancer?
}

\section{Stefan Burdach* and Hans-Jochem Kolb}

Laboratory of Transplantation Biology, Children's Cancer Research Center and Department of Pediatrics, Kinderklinik München Schwabing, Technische Universität München, München, Germany

\section{Edited by:}

Peter Bader, University Hospital, Germany

\section{Reviewed by:}

Arjan Lankester, Leiden University Medical Center, Netherlands

Nabil Ahmed, Baylor College of

Medicine, USA

\section{*Correspondence}

Stefan Burdach, Laboratory of Transplantation Biology, Children's Cancer Research Center and

Department of Pediatrics, Kinderklinik München Schwabing, Technische Universität München, Kölner Platz 1, 80804 München, Germany.

e-mail: stefan.burdach@Irz.tum.de
Men and sharks are both jawed vertebrates at the top of the food chain. Sharks are the first extant to develop adaptive immunity preserved to man throughout jawed vertebrates. We hypothesize here, that T cell receptor/major histocompatibility complex (TCR/MHC) interactions developed as the defense mechanism of carnivors against takeover by their victims' cells derived pathogens. Germline encoded TCR segments have been conserved in evolution, providing the MHC bias of TCR. Ancestor genes of $\mathrm{MHC}$ polymorphisms may have first developed as a mating preference system, that later in evolution provided host immune responses destroying infectious non-self, yet maintaining tolerance to self. Pathogens may thus have simultaneously selected for alloimmunity. Allorejection has been observed in sharks and men. Cannibalism is a common ecological interaction in the animal kingdom, especially prevalent in aquatic communities; it favors selection of intraspecies allo responses for defense of self integrity. Alloreactive T cells do not undergo negative selection of strong TCR/MHC interactions; thus, they react stronger than self-MHC recognizing T cells. High levels of genetic diversity at MHC genes play a critical role in protecting populations of vertebrate species from contagious cells displaying stemness and homing features, including cancer cells. Recognition of self-MHC fails especially in diseases, which predominantly arise with age and after the peak of reproduction, e.g., cancer. So far, the treatment of malignant disease with autologous $T$ cells has widely failed. Allorecognition constitutes an extremely powerful mechanism in evolution, which may be employed in immunotherapy of cancer by MHC-disparate, e.g., haploidentical transplantation and consecutive treatment with $T$ cells from the donor parents recognizing tumor selective peptides presented by the non-inherited haplotype on the tumor.

Keywords: allorestricted T cells, immunotherapy of cancer, haploidentical transplantation, tumor therapy, cellular immunity, adaptive immunity, TCR/MHC evolution

\section{WHAT DO MEN AND SHARKS HAVE IN COMMON?}

They are both jawed vertebrates and at the top of the food chain. Sharks have achieved this by the most powerful jaws on the planet. They were the first big meat eaters (carnivores) in evolution. Because the sharks' teeth are replaceable, they may grow. Sharks may use over 20,000 teeth in its lifetime (Rafferty, 2011). Thus, they represent the paradigm of gnathostomata (jawed vertebrates). It is obvious why these first big meat eaters in evolution were jawed, but why were the first meat eaters also the first to develop adaptive immunity in the animal kingdom? And what may men learn from sharks?

In essence, we hypothesize here, that $\mathrm{T}$ cell receptor/major histocompatibility complex (TCR/MHC) interactions developed as the defense mechanism of carnivors against takeover by their victims' cells or merely the pathogens these cells may carry. Thus, TCR/MHC interaction represents an extremely powerful mechanism in evolution. Such successful mechanisms are to be employed in immunotherapy of cancer.
JAWED VERTEBRATES WERE FIRST CARNIVORS, DISCRIMINATING SELF AND NON-SELF BY ADAPTIVE CELLULAR IMMUUNITY BY MEANS OF V(D)J RECOMBINATION Herein, cognate recognition of auto- as well as allo-MHC is critical. Germline encoded TCR segments have been selected by evolution to promote recognition of MHC, i.e., the MHC bias of TCR (Scott-Browne et al., 2011). This may be the reason why, $\mathrm{T}$ cell receptor $\mathrm{V}(\mathrm{D}) \mathrm{J}$ recombination-based auto and allo-MHC recognition first evolved in the earliest gnathostomata rays and shark 450 million years ago (Litman et al., 2010) in an evolutionary time span estimated to be less than 20 million years (Marchalonis and Schluter, 1998). These huge carnivors were exposed to a tremendous increase in pathogen exposure necessitating the development of versatile recognition systems discriminating between pathogen containing and non-containing cells. Allo and autoMHC recognition are both based on the inherent MHC bias of the TCR

$\mathrm{V}(\mathrm{D}) \mathrm{J}$ recombination-based $\mathrm{MHC}$ recognition occurred by a horizontal transposon insertion of bacterial genes into the vertebrate genome (Agrawal et al., 1998). This insertion placed the 
recombinase activating genes RAG1 and RAG2 into an already existing non-rearranging $\mathrm{V}$-like exon of an Ig-domain-containing gene that was regulating cell mediated cytotoxicity or phagocytosis (Kaufman, 2002; Van Den Berg et al., 2004). The result was a method of rearranging genes to create molecules that had a greater structural diversity than those supplied by the genome for the rest of the vertebrate body. This event for these reasons is so radical and unprecedented that it has been described as a biological "Big Bang” (Schluter et al., 1999). While there has been evolutionary modifications in mammals, even the most basal group of living gnathostomes, the elasmobranchii or cartilaginous fish, contain all its basic elements: MHC class I and class II, Ig, TCR chains $\alpha, \beta$, $\gamma$, and $\delta$ (Rast et al., 1997), and RAG1 and RAG2 (Agrawal et al., 1998; Laird et al., 2000). In spite of extensive search, none of these elements have been found in the phylogenically earlier agnathia (such as lampreys and hagfish) (Roitt et al., 1998; Mayer et al., 2002; Flajnik and Du Pasquier, 2008).

However, there is no evidence that the MHC is derived directly from allorecognition systems occurring earlier in evolution in plants and invertebrates. Such previous allorecognition systems, such as FuHC (fusion/histocompatibility) in the urochordate Botryllus function to defend the genetic integrity of the individual by preventing intraspecific stem cell parasitism as well as self-fertilization and inbreeding (Laird et al., 2005). There is no evidence that these allorecognition systems are ancestors of MHC.

Rather, based on the synteny to olfactorial polymorphisms, it has been assumed, that MHC polymorphisms may have developed as a mating preference system (Potts et al., 1991). In addition, infectious agents selected for host immune responses that destroy infectious non-self, yet maintain tolerance to self. Retroviruses and other pathogens may thus have simultaneously selected for alloimmunity (Gould et al., 2004), because polymorphism was primarily advantageous to the population and maybe secondary advantageous to the genetic integrity of the individual by providing allorecognition and allorejection.

\section{WHAT CAME FIRST: ALLOREACTIVITY OR THE "CONVENTIONAL IMMUNE RESPONSE" DIRECTED AGAINST PEPTIDES PRESENTED BY SELF-MHC?}

To answer this question, it may be helpful to compare MHC and TCR variability: Precedence of MHC variability before TCR variability, would argue in favor of peptide recognition and the conventional immune response. In contrast, precedence of TCR variability before MHC variability would argue in favor of allo$\mathrm{MHC}$ reactivity. In that case, invariant $\mathrm{MHC}$ would have been too primitive for versatile peptide binding. Kurosawa and Hashimoto (1997) argues that MHC variability came in before TCR variability, i.e., first, there was only one TCR. These assumptions are based on the postulate, that allorecognition is MHC dominant. However there is also evidence that allorecognition may be peptide dominant (Felix and Allen, 2007). Moreover, the recent discovery, that a single amino acid in the TCR CDR2 is conserved from shark to man and is critical for MHC recognition by TCR (Scott-Browne et al., 2011) would argue in favor of MHC recognition before peptide recognition. This finding underlines Nils Jerne's postulate of a germ line encoded, innate MHC bias of the random TCR repertoire, located in MHC binding CDR1 and CDR2. Nevertheless, sharks do have a thymus and are capable of peptide selection (Roitt et al., $1998)$. However, $\gamma / \delta$ TCR is capable of recognizing antigen independent of MHC and is likely to have preceded $\alpha / \beta$ TCR. We conclude, that based on the inherent TCR/MHC affinity, these two systems have developed simultaneously (Table 1).

Allorejection has been observed in the rudimentary from of chronic graft rejection in elamosbranchs, including sharks (Kurosawa and Hashimoto, 1997). Allorejection has been observed in sharks and men, although it is not restricted to gnathostomata. However, allorecognition by adaptive cellular immunity by means of $\mathrm{V}(\mathrm{D}) \mathrm{J}$ recombination is restricted to gnathostomata. Thus, allo$\mathrm{MHC}$ recognition may be essential in carnivorous vertebrates for self defense (Figure 1).

Of interest, while mechanisms of adaptive immunity are conserved in evolution from sharks to men, innate immunity displays great interspecies variation of mechanisms, although T and NK cells have both common ancestors and a common way to kill (granzyme/perforin). $\gamma / \delta$ T cells may bridge adaptive and innate immunity by combining adaptive features independent of MHC with rapid, innate-like responses (Vantourout and Hayday, 2013).

\section{ALLOREACTIVITY AND THE SCHWABING CARNIVOR HYPOTHESIS OF SUPERIORITY OF MHC ALLORESTRICTED T CELLS IN IMMUNOTHERAPY OF CANCER}

Hitherto, the selective pressure for allorecognition has remained even more of an enigma for the scientific community than the mechanism allorecognition itself (Felix and Allen, 2007). Allorecognition has drawn the attention of immunologists in the context of transplantation, a relatively new phenomenon in evolution, not able to display selective pressure. However, devouring of raw meat of the same species containing viruses and other parasites represents a selective pressure for MHC recognition and the development of allorejection. Since agnathan shark prey such as lamprey and hagfish did not display MHC, selective pressure for allorecognition to defend individual genetic integrity occurred first, when sharks started eating sharks: cannibalism became a constitutive feature of this extant, but not restricted to it. In zoology, cannibalism is

\section{Table 1 | The Schwabing Carnivor Hypothesis of Superiority of MHC allorestricted T cells in Immunotherapy of Cancer.}

$\mathrm{MHC}$ polymorphisms may have first developed as a mating preference system, that later in evolution provided host immune responses destroying infectious non-self, yet maintaining tolerance to self

Pathogens may thus have simultaneously selected for alloimmunity

Alloreactive $\mathrm{T}$ cells do not undergo negative selection of strong TCR/MHC interactions; thus, they react stronger than self-MHC recognizing $\mathrm{T}$ cells

So far, the treatment of malignant disease with autologous T cells has widely failed

Allorecognition constitutes an extremely powerful mechanism in evolution, which may be employed in immunotherapy of cancer

Haploidentical transplantation and consecutive treatment with $T$ cells from the donor parents recognize tumor selective peptides presented by the non-donor parent haplotype on the tumor 


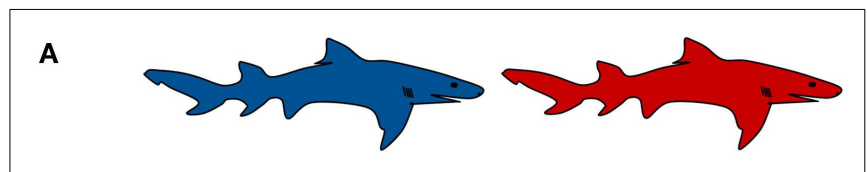

later...

B
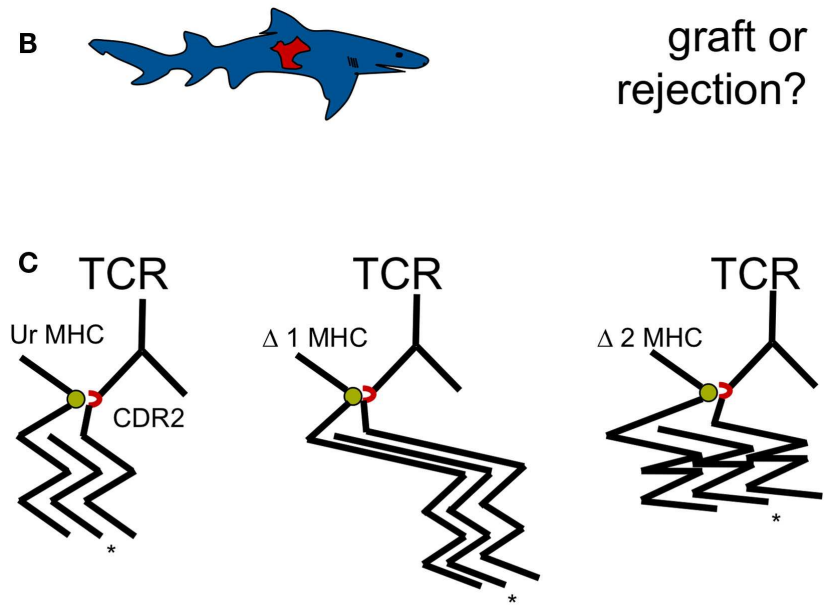

* INSDP (Infectious Non Self Derived Peptide)

FIGURE 1 | (A,B) Allorecognition by adaptive cellular immunity by means of $\mathrm{V}(\mathrm{D}) \mathrm{J}$ recombination is restricted to gnathostomata. Allo-MHC recognition may be essential in carnivorous vertebrates for self defense. Devouring of raw meat of the same species containing viruses and other parasites represents a selective pressure for $\mathrm{MHC}$ recognition and the development of allorejection. Since agnathan shark prey such as lamprey and hagfish did not display MHC, selective pressure for allorecognition to defend individual genetic integrity occurred first, when sharks started eating sharks: cannibalism became a constitutive feature of this extant. (C) A single amino acid in the TCR CDR2 (red), conserved from shark to man and critical for $\mathrm{MHC}$ recognition (green) by TCR argues in favor of $\mathrm{MHC}$ recognition before peptide recognition and underlines the postulate of a germ line encoded, innate $\mathrm{MHC}$ bias of the random TCR repertoire, located in $\mathrm{MHC}$ binding CDR1 and CDR2.

a common ecological interaction in the animal kingdom and has been recorded for more than 1500 species (Polis, 1981). It commonly occurs under natural conditions in a variety of species, including man (Elgar and Crespi, 1992) Cannibalism seems to be especially prevalent in aquatic communities, in which up to approximately $90 \%$ of the organisms engage in cannibalism at some point of the life cycle (Fox, 1975). Injuries violating epidermal and mucosal barriers during shark fights with ensuing cannibalism may have facilitated chimerism. Thus, it is not completely clear weather defense against prey derived pathogens alone or the prey itself as well was the driving force of development of adaptive immunity (Marchalonis and Schluter, 1998; Klimovich, 2002; Marchalonis et al., 2002). The consideration, that "there is a growing tendency to regard the evolutionary origin of adaptive immunity as being related to something other than defense against pathogenic microorganisms" has been attributed to Burnet himself (Rinkevich, 2004). Rationales of its development include the defense of host integrity against cells from the same or other species, and that it aided the management of symbiosis with commensals (Klimovich, 2002; McFall-Ngai, 2002).

Cellular adaptive immunity probably preceded humoral adaptive immunity in evolution (Parham, 1992). In jawless vertebrates (agnathia), e.g., lamprey and hagfish, leucine-rich repeat variants (LRR) function as variable lymphoid receptors (VLR), the forerunners of $\mathrm{T}$ cell receptors and immunoglobulins (Rast et al., 1997). Adaptive cellular immunity based on V(D)J recombination and $\mathrm{MHC}$ recognition developed, according to our reasoning, first to protect the carnivor organism from foreign invasion by takeover by the cells of the victims of its cannibalism and/or from infection by the viruses, the devoured cells contained. Consecutively, the recognition of self-MHC by V(D)J recombination-based adaptive immunity may have developed simultaneously with allorecognition, both as critical mechanisms for defense of the biological ego against infection and non-self. In fact, alloreactivity has much more in common with the conventional immune response than previously thought.

Since alloreactive $T$ cells did not undergo negative selection of strong TCR/MHC interactions, they react stronger than self-MHC recognizing $T$ cells. Another hallmark of alloreactivity is the high precursor frequency of alloreactive T cells, which is 100-fold to 1,000-fold higher than the precursor frequency of T cells specific for any single foreign-peptide-self-MHC complex (Lindahl and Wilson, 1977). The high frequency of alloreactive T cells ( 1 in $10^{3}-$ $10^{4}$ ) enables their detection during a primary immune response, a defining feature of alloreactivity (Felix and Allen, 2007). Given the high frequency of alloreactive T cells may be of importance, as well, for immunotherapy with transgenic allorestricted $T$ cells, since this population constitutes the target population of the transgene.

The importance of alloreactivity for protection against non-self is illustrated, e.g., by a transplantable tumor in the Tasmanian devil, a large carnivorous Australian marsupial. Transmission of this fatal clonal tumor by biting occurs due to depleted MHC diversity and threatens the devil with extinction (Siddle et al., 2007). High levels of genetic diversity at MHC genes play a critical role in protecting populations of vertebrate species from contagious cancer, of which two forms do exist, which are either transmitted by biting (as in the Devil Facial Tumor Disease, DFTD) or by sexual contact (as in case of the Canine Transmissible Venereal Tumor, CTVT, e.g., in Bernadine dogs) (Mello Martins et al., 2005). Species that have undergone genetic bottlenecks and have lost diversity at MHC genes are at risk of transmissible tumors. Moreover, evolution and selection for tumor variants capable of evading the immune response allow contagious cancers to cross MHC barriers (Belov, 2011). This could also apply to other cells displaying stemness and homing features after being devoured by carnivores (Table 1).

In contrast to allorecognition, recognition of auto-MHC is not triggering effective $\mathrm{T}$ cell responses in all situations, given the risks of autoimmunity. Auto-MHC responses fail especially in diseases, whose elimination is evolutionary not imperative, e.g., cancer. We perceive the co-evolution of tumor and host imprinted immuno-editing as the general cause of the failure of immune surveillance of cancer, yielding escape of the tumor from immune surveillance. 
Thus far, the treatment of malignant disease with autologous $T$ cells has been effective only in part; although a plethora of approaches has been developed including activation of the antitumor response through vaccination, promoting $\mathrm{T}$ cell function by leadfooting their accelerators and turning off their brakes, expanding existing tumor reactive $\mathrm{T}$ cells by adoptive $\mathrm{T}$ cell therapy, redirecting $\mathrm{T}$ cells utilizing TCR transduction, e.g., chimeric antigen receptor (CAR) engineering (Gao et al., 2013). Most advanced results are being seen in melanomas for the former (Restifo et al., 2012) and some in chronic lymphocytic leukemia and myeloma for the latter, i.e., the CAR approach (Maus and June, 2013). These advances may well be complemented and lead into a new dimension by employment of allorestricted $\mathrm{T}$ cells. The success of allo-MHC recognition by adaptive immunity both in terms of the evolutionary success of the defense of the biological ego in carnivorous vertebrates, as well as with respect to allorejection in $\mathrm{MHC}$-disparate organ transplantation, constitutes a rationale for employment of alloreactive $T$ cells in antineoplastic immunotherapy (Stauss, 1999) not only in hematopoietic malignancies (Kolb et al., 1990) but also in other

\section{REFERENCES}

Agrawal,A., Eastman, Q. M., and Schatz, D. G. (1998). Transposition mediated by RAG1 and RAG2 and its implications for the evolution of the immune system. Nature 394, 744-751.

Belov, K. (2011). The role of the major histocompatibility complex in the spread of contagious cancers. Mamm. Genome 22, 83-90.

Burdach, S., Van Kaick, B., Laws, H. J., Ahrens, S., Haase, R., Korholz, D., et al. (2000). Allogeneic and autologous stem-cell transplantation in advanced Ewing tumors. An update after long-term follow-up from two centers of the European Intergroup study EICESS. Ann. Oncol. 11, 1451-1462.

Elgar, M. A., and Crespi, B. E. (1992). Cannibalism: Ecology and Evolution Among Diverse Taxa. Oxford: Oxford University Press.

Felix, N. J., and Allen, P. M. (2007). Specificity of T-cell alloreactivity. Nat. Rev. Immunol. 7, 942-953.

Flajnik, M., and Du Pasquier, L. (2008). "Evolution of the immune system," in Fundamental Immunology, ed. W. E. Paul (Philadelphia: Wolters Kluwer), 56-124.

Fox, L. R. (1975). Cannibalism in natural-populations. Annu. Rev. Ecol. Syst. 6, 87-106.

Gao, J., Bernatchez, C., Sharma, P., Radvanyi, L. G., and Hwu, P. (2013). Advances in the development of cancer immunotherapies. Trends Immunol. 34, 90-98.

Gould, S. J., Hildreth, J. E. K., and Booth, A. M. (2004). The evolution of alloimmunity and the genesis of adaptive immunity. Q. Rev. Biol. 79, 359-382.

Kaufman, J. (2002). The origins of the adaptive immune system: whatever next? Nat. Immunol. 3, 1124-1125.

Klimovich, V. (2002). Actual problems of evolutional immunology. Zh. Evol. Biokhim. Fiziol. 38, 442-451.

Kolb, H. J., Mittermuller, J., Clemm, C., Holler, E., Ledderose, G., Brehm, G., et al. (1990). Donor leukocyte transfusions for treatment of recurrent chronic myelogenous leukemia in marrow transplant patients. Blood 76, 2462-2465.

Kurosawa, Y., and Hashimoto, K. (1997). How did the primordial T cell receptor and MHC molecules function initially. Immunol. Cell Biol. 75, 193-196.

Laird, D. J., De Tomaso, A. W., Cooper, M. D., and Weissman, I. L. (2000). 50 Million years of chordate evolution: seeking the origins of adaptive immunity. Proc. Natl. Acad. Sci. U.S.A. 97, 6924-6926.

Laird, D. J., De Tomaso, A. W. and Weissman, I. L. (2005). Stem cells are units of natural selection in a colonial ascidian. Cell 123, 1351-1360.

Lindahl, K. F., and Wilson, D. B. (1977). Histocompatibility antigenactivated cytotoxic $\mathrm{T}$ lymphocytes. II. Estimates of the frequency and specificity of precursors. J. Exp. Med. 145, 508-522.

Litman, G. W., Rast, J. P., and Fugmann, S. D. (2010). The origins of

mesenchymal neoplasias, such as sarcomas (Burdach et al., 2000) (Figure 1).

\section{CONCLUSION}

In essence we postulate here, that TCR/MHC interactions developed as a defense mechanism of gnathostomata against takeover by their victims' cells and/or their deleterious viral load. Allorecognition constitutes an extremely powerful mechanism in evolution, which may be employed in immunotherapy of cancer by e.g., haploidentical transplantation and consecutive treatment with $\mathrm{T}$ cells from the donor parents recognizing tumor selective peptides presented by the non-donor parent haplotype on the tumor. In addition, the application of alloreactivity, can be extended to mismatched unrelated transplants including umbilical cord blood transplants. Taken together, $\mathrm{T}$ cell reactivity toward allo-MHC, i.e., to inherited non-donor MHC alleles, can be advantageous in cancer therapy. This assumption may be dubbed the Schwabing Carnivor Hypothesis of Superiority of MHC allorestricted $T$ cells in Immunotherapy of Cancer (SCHySM).

vertebrate adaptive immunity. Nat. Rev. Immunol. 10, 543-553.

Marchalonis, J. J., Kaveri, S., LacroixDesmazes, S., and Kazatchkine, K. (2002). Natural recognition repertoire and the evolutionary emergence of the combinatorial immune system. FASEB J. 16, 842-848.

Marchalonis, J. J., and Schluter, S. F. (1998). A stochastic model for the rapid emergence of specific vertebrate immunity incorporating horizontal transfer of systems enabling duplication and combinatorial diversification. J. Theor. Biol. 193, 429-444

Maus, M. V., and June, C. H. (2013) Zoom zoom: racing CARs for multiple myeloma. Clin. Cancer Res. 19, 1917-1919.

Mayer, W. E., Uinuk-Ool, T., Tichy, H., Gartland, L. A., Klein, J., and Cooper M. D. (2002). Isolation and characterization of lymphocyte-like cells from a lamprey. Proc. Natl. Acad. Sci. U.S.A. 99, 14350-14355

McFall-Ngai, M. J. (2002). Unseen forces: the influence of bacteria on animal development. Dev. Biol. 242, $1-14$.

Mello Martins, M. I., De Souza, F. F., and Gobello, C. (2005). "Canine transmissible venereal tumor: etiology, pathology, diagnosis and treatment," in Recent Advances in Small Animal Reproduction, eds P. W. Concannon, G. England, J. Verstgegen III, and C. Linde-Forsberg (Ithaca: International Veterinary Information Service), A1233.0405.

Parham, P. (1992). Immunology. Deconstructing the MHC. Nature 360, 300-301
Polis, G. A. (1981). The evolution and dynamics of intraspecific predation. Annu. Rev. Ecol. Syst. 12, 225-251.

Potts, W. K., Manning, C. J., and Wakeland, E. K. (1991). Mating patterns in seminatural populations of mice influenced by MHC genotype. Nature 352, 619-621.

Rafferty, J. P. (2011). Meat Eaters: Raptors, Sharks, and Crocodiles. New York: Rosen Publishing Group, Inc.

Rast, J. P., Anderson, M. K., Strong, S. J. Luer, C., Litman, R. T., and Litman, G. W. (1997). Alpha, beta, gamma and delta $\mathrm{T}$ cell antigen receptor genes arose early in vertebrate phylogeny. Immunity 6, 1-11.

Restifo, N. P., Dudley, M. E., and Rosenberg, S. A. (2012). Adoptive immunotherapy for cancer: harnessing the $\mathrm{T}$ cell response. Nat. Rev. Immunol. 12, 269-281.

Rinkevich, B. (2004). Primitive immune systems: are your ways my ways? Immunol. Rev. 198, 25-35.

Roitt, I., Brostoff, J., and Male, D. (eds). (1998). "Evolution of immunity," in Immunologie, 5th Edn (London: Mosby), 199-220.

Schluter, S. F., Bernstein, R. M., Bernstein, H., and Marchalonis, J. J. (1999). "Big Bang" emergence of the combinatorial immune system. Dev. Comp. Immunol. 23, 107-111.

Scott-Browne, J. P., Crawford, F., Young, M. H., Kappler, J. W., Marrack, P., and Gapin, L. (2011). Evolutionarily conserved features contribute to alpha beta $\mathrm{T}$ cell receptor specificity. Immunity 35 , 526-535. 
Siddle, H. V., Kreiss, A., Eldridge, M. D. B., Noonan, E., Clarke, C. J., Pyecroft, S., et al. (2007). Transmission of a fatal clonal tumor by biting occurs due to depleted MHC diversity in a threatened carnivorous marsupial. Proc. Natl. Acad. Sci. U.S.A. 104, 16221-16226.

Stauss, H. J. (1999). Immunotherapy with CTLs restricted by nonself MHC. Immunol. Today 20, 180-183.

Van Den Berg, T. K., Yoder, J. A., and Litman, G. W. (2004). On the origins of adaptive immunity: innate immune receptors join the tale. Trends Immunol. 25, 11-16.

Vantourout, P., and Hayday, A. (2013). Six-of-the-best: unique contributions of $\gamma \delta \mathrm{T}$ cells to immunology. Nat. Rev. Immunol. 13, 88-100.

Conflict of Interest Statement: The authors declare that the research was conducted in the absence of any commercial or financial relationships that could be construed as a potential conflict of interest.

Received: 31 January 2013; paper pending published: 06 March 2013; accepted: 10 April 2013; published online: 03 May 2013.

Citation: Burdach $\mathrm{S}$ and Kolb $\mathrm{H}-\mathrm{J}$ (2013) The vigor of defense against non-self: potential superiority of allorestricted $T$ cells in immunotherapy of cancer? Front. Oncol. 3:100. doi 10.3389/fonc.2013.00100
This article was submitted to Frontiers in Pediatric Oncology, a specialty of Frontiers in Oncology.

Copyright (c) 2013 Burdach and Kolb. This is an open-access article distributed under the terms of the Creative Commons Attribution License, which permits use, distribution and reproduction in other forums, provided the original authors and source are credited and subject to any copyright notices concerning any third-party graphics etc. 